\title{
Population Status, Distribution, and Threats of Colobus guereza gallarum in Bale Mountains National Park, Southeastern Ethiopia
}

\author{
Israel Petros ${ }^{1,}$, Sefi Mekonen ${ }^{2}$, Hussein Gena $^{3}$, Yared Mesfin ${ }^{4}$ \\ ${ }^{1}$ Department of Biology, College of Natural Sciences, Dilla University, Dilla, Ethiopia \\ ${ }^{2}$ Department of Ecotourism and Wildlife Management, College of Agriculture and Natural Resources, Wolkite University, Wolkite, Ethiopia \\ ${ }^{3}$ Department of Ecotourism and Biodiversity Conservation, College of Agriculture and Natural Resources, Madda Walabu University, Robe, \\ Ethiopia \\ ${ }^{4}$ Department of Natural Resource Management, College of Agriculture and Environmental Sciences, Arsi University, Assela, Ethiopia
}

\section{Email address:}

peterisri.4banch@gmail.com (I. Petros), mekonen.sefi@gmail.com (S. Mekonen), huseenkoo@gmail.com (H. Gena),

dreyaman@gmail.com (Y. Mesfin)

${ }^{*}$ Corresponding author

\section{To cite this article:}

Israel Petros, Sefi Mekonen, Hussein Gena, Yared Mesfin. Population Status, Distribution, and Threats of Colobus guereza gallarum in Bale Mountains National Park, Southeastern Ethiopia. International Journal of Natural Resource Ecology and Management.

Vol. 3, No. 3, 2018, pp. 39-45. doi: 10.11648/j.ijnrem.20180303.12

Received: June 28, 2018; Accepted: July 13, 2018; Published: August 8, 2018

\begin{abstract}
Colobus guereza gallarum is the subspecies of Colobus monkey (Colobus guereza) restricted to the Ethiopian highlands to the east of the Rift Valley. This study was carried out from February to June 2016 to provide data on Population status, distribution, and threats of C. g. gallarum in Bale Mountains National Park. Line transects with 5 km distance were made in all survey areas to estimate the whole population in the area. Field visits and questionnaire distribution were made to assess community perception and threats to the species. The major population of C. g. gallarum was observed in Rira. A total of 116 and 113 individuals were observed in the wet and dry seasons, respectively. There was no significant difference between wet and dry seasons $(\mathrm{F}=0.072, \mathrm{df}=1, \mathrm{p}=0.795)$ of the population size of $\mathrm{C}$. g. gallarum. Out of 229 individuals of guereza counted in both dry and wet seasons, 44 were adult males, 58 adult females, 42 sub-adult males, 43 sub-adult females and the remaining 42 were young individuals. However, as t-test indicated, here was no significant difference between wet and dry seasons in a number of in this sex and age categories $(\mathrm{P}>0.70)$. The male to female ratio was 1.00:1.1, while, the age ratio of young to all other individuals was 1.00:4.45. Here also, the ratio of young to an adult female was 1.00:1.40 and 1.00:1.36 during dry and wet seasons, respectively. The response of communities indicated the presence of positive perception towards the species due to its main importance for tourism and cultural aspect of the communities. Moreover, habitat destruction due to logging, farmland expansion and settlement were main observed threats to species in the area.
\end{abstract}

Keywords: Colobus guereza gallarum, Distribution, Population Structure, Threats

\section{Introduction}

The Ethiopian highland massif is accounted to cover over $80 \%$ of the land in Africa that occur at an altitude of $3000 \mathrm{~m}$ asl and this may be a major reason for many endemic animals and plants to occur in Ethiopia [1]. One of the highland ecosystems in Ethiopia is, the Bale Mountains National Park (BMNP) which was first proposed in the late 1960s to protect
Afroalpine habitat and populations of the rare and endemic species [2, 3]. It was established by the Ethiopian Wildlife Conservation Organization (EWCO) in 1971 with the primary objective of conserving the wildlife and other valuable natural resources in the area. It is a home for mammals such as Mountain nyala (Tragelaphus buxtoni) and the Ethiopian wolf (Canis simensis) which are endemic to the country.

The Bale Mountains National Park (BMNP) comprises 
primates including the Bale Vervet monkey (Chlorocebus djamdjamensis) and Black-and-white colobus (Colobus guereza). One of these primates is, Colobus guereza gallarum which is among the subspecies of black and white colobus monkey (Colobus guereza) that are distributed in central and eastern African countries including Ethiopia. Colobus guereza gallarum is restricted to east of the rift valley occupying the highland ecosystems in southeastern Ethiopia [4].

However, little is known about the status of black and white colobus monkey (Colobus guereza) species. Even, C. g. gallarum is recorded as "Data Deficient" in the IUCN Red List of Threatened Species category. Moreover, it is facing the challenge of habitat destruction. In the absence of recent survey work, it is not known how much pressure this population is under [4]. Clearance of forests for agriculture is a major concern for black and white colobus monkey which has a relatively small range in East Africa [5]. Hence, understanding the population status and threats of this species were found to be essential for better conservation effort and economic values from tourism. However, the population status, distribution, and threats have not been documented. Moreover, there was no detail investigation made to assess the status and threats of this species.

The study of population status and distribution is crucial to assess the habitat requirements of this species [6]. Identifying the habitat requirement of the species contributes to conservation mechanism of the species in the park. Knowledge of habitat requirement and distribution along the environmental gradient is essential not only for the species survival but also for the sustainable management and conservation of protected areas [7].

Therefore, the main objective of this research was to study population status, distribution, and threats of this data deficient primate species in BMNP. The result of this research has a great importance for science and conservation measures on $C$. g. gallarum in the study area. This provides relevant information for BMNP, local communities and regional administration, conservation organizations and other concerned bodies about the status of the species, threats and basic information on its distribution. Due to its attractive nature, it directly or indirectly contributes to ecotourism development. Moreover, it enhances the conservation values as well as related benefits of communities in the area.

\section{Method}

\subsection{Study Area Description}

The study was conducted in the Bale Mountains National Park (BMNP) in the Oromiya administrative regional state southeast Ethiopia. BMNP is found $440 \mathrm{~km}$ far from the central city of the country, Addis Ababa and located at $6^{\circ} 29^{\prime}$ $-7^{\circ} 10^{\prime} \mathrm{N}$ and $39^{\circ} 28^{\prime}-39^{\circ} 57^{\prime} \mathrm{E}$. The park belongs to the BaleArsi massif, which forms the western section of the southeastern Ethiopian highlands covering $2200 \mathrm{~km}^{2}$ [8, 9]. The BMNP is one of the parks in Ethiopia that harbor a diverse range of endemic fauna and flora and is part of the Eastern Afromontane Biodiversity Hotspot [10]. It is also one of the 34 international biodiversity hotspots and qualities for the World Heritage Site and Biosphere reserve listing with area coverage of 2,200 $\mathrm{km}^{2}$ of mountains and forest [3].

It was first proposed in the late 1960s to protect Afroalpine habitat and populations of the rare, endemic and species of the mountain nyala (Tragelaphus buxtoni) and the Ethiopian wolf (Canis simensis) [3, 11]. Even if its establishment was for this, Bale Mountains is one of the most important areas of the world for its number of threatened Ethiopian endemics in all taxa $26 \%$ of Ethiopia's endemic species (1 primate (Bale Monkey), 1 bovid, 1 hare and 8 species of rodent) are found in the area, including the entire global population of the giant molerat (Trachyoryctes macrocephalus). Of the area's recorded birds, $6 \%$ are Ethiopian endemics. In addition, there are several rare and endemic amphibian species found only in Bale as well as 1321 species of flowering plants with 163 endemic (23 to Bale alone) to Ethiopia.

Methods of Data Collection

\subsection{Distribution and Population Structure}

The population structure of Colobus guereza gallarum in the study areas was carried out using line-transect survey. The study area has various types of habitats. Sample blocks were established in different sites i.e. Headquarter of the park (Dinsho Site), Gayssay grassland, Northern woodland and Harenna forest (Rira). During the transect survey, time of the sighting, location along census route, number of monkeys present, perpendicular transect to animal distance and observer to animal distance was recorded [12]. We also recorded the presence and location of threats such as logging, farming, settlement, livestock presence and other direct disturbances (i.e., taking place during our sampling) or in the past [13].

Each transect was censused more than times during both the wet and dry seasons [14]. Surveys were conducted on transects from 06:30 -06:45 to 10:30-10:45 $\mathrm{h}$ in the morning and from 14:00 to $18: 00 \mathrm{~h}$ in the afternoon (Peres, 1999) at an average speed of $1 \mathrm{~km} / \mathrm{hr}$ in the forest or $2 \mathrm{~km} / \mathrm{hr}$ in the plantation $[15,16]$.

The transect survey was designed in a straightforward systematic design with a random start. A total length of $120 \mathrm{~km}$ was done in the whole part of the park. Each transect line had 100 to $300 \mathrm{~m}$ width in different sites of the park. The survey was carried out using a compass to measure the perpendicular distance and to count the population within this site. The length of transects increases for large areas so as make them proportional. Every $1 \mathrm{~km}$ transects cover $10 \mathrm{~km}$ of the survey block.

\subsection{Conservation Problem and Community Perception}

The anthropogenic factor of the local people to the $C . g$. the gallarum monkey was determined by physical observations of the site, interviewing the local people to assess their attitude towards the study species and providing 
a questionnaire for varies stake holders concerning the different influences on this species. To determine the sample size of respondents, we used Finite Population Correction in [17].

$$
\mathrm{n}=\mathrm{n}_{0} / 1+\left(\mathrm{n}_{0}-1\right) / \mathrm{N}
$$

Where;

$\mathrm{n}$ is the sample size

$\mathrm{N}$ is the population size.

\section{Result}

From the transect count of Colobus guereza gallarum different sites in Bale Mountains National park, the higher population was recorded in Rira (196) exceeding BMNP head quarter (Dinsho) (8), Gaysey grassland (14) and Northern woodlands (10) (Figure 1).

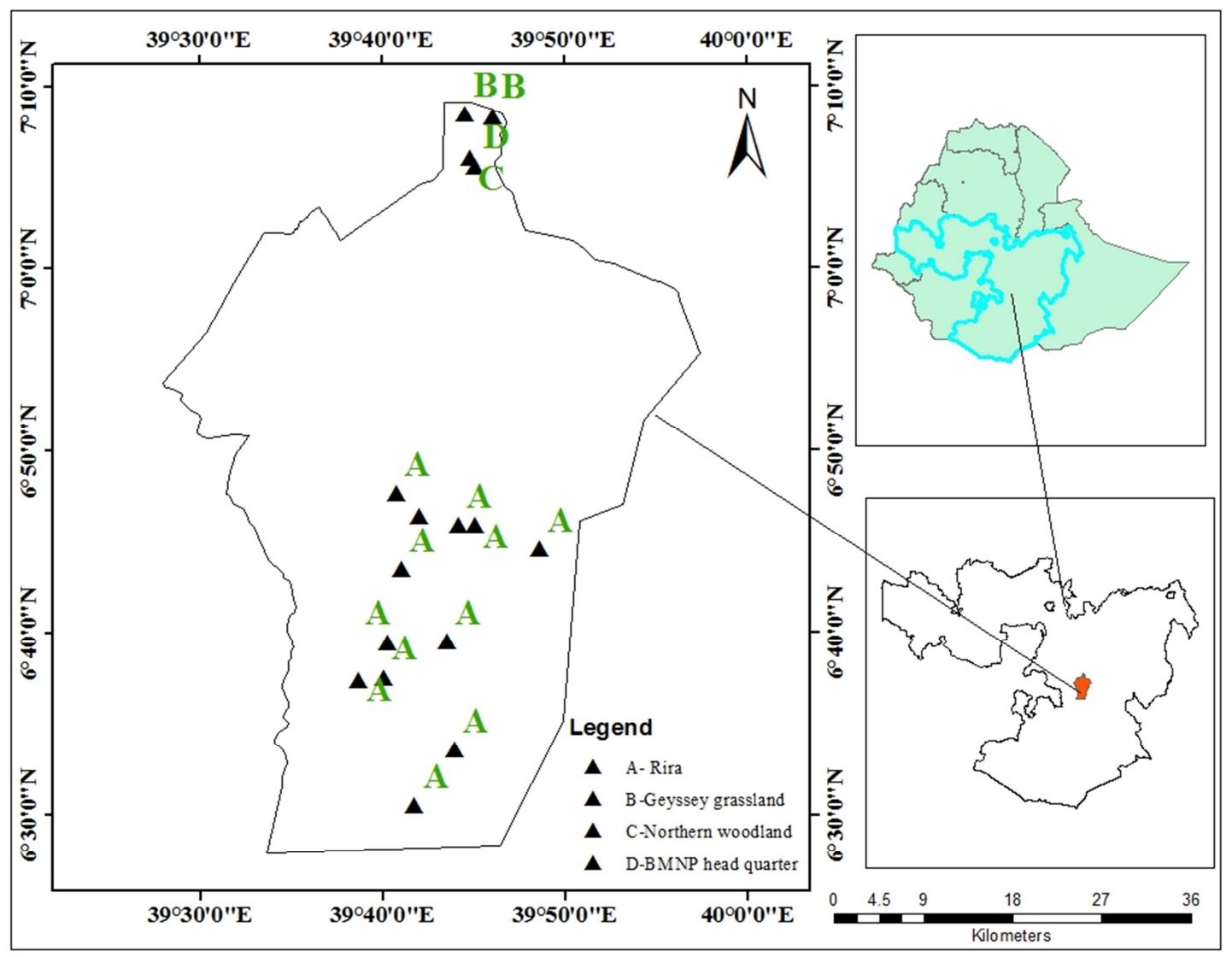

Figure 1. Distribution of C. guereza gallarum in $B M N P$.

A total of 116 and 113 individuals were observed in the wet and dry seasons, respectively (Table $1 \& 2$ ). During the wet season, a total of 116 Colobus guereza gallarum were counted. Among these, 21 were adult males, 30 were adult females, 21 were sub-adult males, 22 were sub adult females and 22 were young individuals. The number of adult females was higher than adult males, subadult males, sub-adult females and young during the wet season (Table 1).

Table 1. Population Status of Colobus guereza gallarum during the wet season.

\begin{tabular}{|c|c|c|c|c|c|c|c|}
\hline Sites & Transect No. & Adult male & Adult female & Sub-adult male & Sub-adult female & Young & Mean $( \pm$ SE) \\
\hline \multirow{11}{*}{ Rira } & 1 & 1 & 2 & 1 & 2 & 1 & $1.40 \pm 0.55$ \\
\hline & 2 & 3 & 4 & 3 & 3 & 4 & $3.40 \pm 0.55$ \\
\hline & 3 & 1 & 1 & 0 & 1 & 0 & $0.60 \pm 0.55$ \\
\hline & 5 & 1 & 1 & 1 & 1 & 1 & $1.00 \pm 0.00$ \\
\hline & 6 & 2 & 2 & 1 & 1 & 2 & $1.60 \pm 0.55$ \\
\hline & 7 & 1 & 1 & 0 & 1 & 1 & $0.80 \pm 0.45$ \\
\hline & 9 & 2 & 2 & 3 & 2 & 1 & $2.00 \pm 0.71$ \\
\hline & 10 & 2 & 3 & 3 & 3 & 3 & $2.80 \pm 0.45$ \\
\hline & 11 & 1 & 1 & 2 & 1 & 1 & $1.20 \pm 0.45$ \\
\hline & 12 & 0 & 0 & 0 & 0 & 0 & $0.00 \pm 0.00$ \\
\hline & 13 & 1 & 2 & 1 & 2 & 0 & $1.20 \pm 0.84$ \\
\hline
\end{tabular}




\begin{tabular}{llllllll}
\hline Sites & Transect No. & Adult male & Adult female & Sub-adult male & Sub-adult female & Young & Mean $( \pm$ SE) \\
\hline & 14 & 0 & 0 & 0 & 0 & 0 & $0.00 \pm 0.00$ \\
BMNP Head Quarter & 15 & 1 & 1 & 0 & 0 & 0 & $0.40 \pm 0.55$ \\
Gayssey Grassland & 16 & 0 & 0 & 0 & 0 & 0 & $0.00 \pm 0.00$ \\
& 17 & 1 & 2 & 0 & 0 & 1 & $0.80 \pm 0.84$ \\
Northern woodland & 18 & 0 & 0 & 0 & 0 & 0 & $0.00 \pm 0.00$ \\
Total & 19 & 1 & 1 & 1 & 22 & 0 & $0.80 \pm 0.45$ \\
\hline
\end{tabular}

During the dry season, lower number of the total population was recorded. The number of adult females exceeds adult males, sub-adult males, sub-adult females and young individuals. There are relatively similar numerical figures in the number of sub-adults and young individuals during the dry period (Table 2).

Table 2. Population structure of Colobus guereza gallarum during the dry season.

\begin{tabular}{|c|c|c|c|c|c|c|c|}
\hline Sites & Transect No. & Adult male & Adult female & Sub-adult male & Sub-adult female & Young & Mean $( \pm$ SE $)$ \\
\hline \multirow{13}{*}{ Rira } & 1 & 1 & 1 & 1 & 1 & 2 & $1.20 \pm 0.447$ \\
\hline & 2 & 3 & 4 & 2 & 2 & 2 & $2.60 \pm 0.894$ \\
\hline & 3 & 1 & 1 & 0 & 1 & 0 & $0.60 \pm 0.55$ \\
\hline & 4 & 0 & 0 & 0 & 0 & 0 & $0.00 \pm 0.00$ \\
\hline & 5 & 0 & 0 & 0 & 0 & 0 & $0.00 \pm 0.00$ \\
\hline & 6 & 2 & 2 & 2 & 1 & 2 & $1.80 \pm 0.45$ \\
\hline & 7 & 2 & 1 & 2 & 2 & 1 & $1.6 \pm 0.55$ \\
\hline & 9 & 2 & 3 & 2 & 2 & 1 & $2.00 \pm 0.71$ \\
\hline & 10 & 2 & 3 & 3 & 3 & 3 & $2.8 \pm 0.45$ \\
\hline & 11 & 2 & 2 & 3 & 2 & 2 & $2.2 \pm 0.45$ \\
\hline & 12 & 2 & 1 & 2 & 2 & 0 & $1.4 \pm 0.90$ \\
\hline & 13 & 0 & 0 & 0 & 0 & 0 & $0.0 \pm 0.00$ \\
\hline & 14 & 1 & 1 & 1 & 1 & 1 & $1.0 \pm 0.00$ \\
\hline BMNP Head Quarter & 15 & 2 & 3 & 1 & 0 & 2 & $1.6 \pm 1.14$ \\
\hline \multirow{2}{*}{ Northern woodland } & 18 & 1 & 2 & 0 & 1 & 2 & $1.2 \pm 0.84$ \\
\hline & 19 & 0 & 0 & 0 & 0 & 0 & $0.0 \pm 0.00$ \\
\hline Total & & 23 & 28 & 21 & 21 & 20 & $22.60 \pm 3.21$ \\
\hline
\end{tabular}

Table 3. Age and sex categories of Colobus guereza gallarum observed during dry and wet seasons.

\begin{tabular}{lllll}
\hline No & Social Class & Wet season & Dry season & Total \\
\hline 1 & Adult Male & 21 & 23 & 44 \\
2 & Adult Female & 30 & 28 & 58 \\
3 & Sub-Adult Male & 21 & 21 & 42 \\
4 & Sub-Adult Female & 22 & 21 & 43 \\
5 & Young & 22 & 20 & 42 \\
Total & & 116 & 113 & 229 \\
\hline
\end{tabular}

Population Structure

The comparison of population structure during the wet and dry of the observed Colobus guereza gallarum in the Bale Mountains National Park are given in Table 3. Out of 229 individuals of guereza counted in both dry and wet seasons, 44 are adult males, 58 adult females, 42 sub-adult males, $43 \%$ sub-adult females and the remaining 42 were young individuals (Table 3). Two independent t-test in different transects indicated that there was no significant difference between wet and dry seasons in number of adult males $(\mathrm{t}=$ $0.375, \mathrm{df}=36, \mathrm{p}=0.710)$, adult females, $(\mathrm{t}=0.275, \mathrm{df}=36$, $\mathrm{p}=0.799)$, subadult males $(\mathrm{t}=0.00, \mathrm{df}=36, \mathrm{p}=1.00)$, sub-adult females, $(\mathrm{t}=0.166, \mathrm{df}=36, \mathrm{p}=0.869)$ and young individuals, $(t=0.266, d f=36, p=0.799)$.

The male to female ratio of Colobus guereza gallarum was 1.00:1.17. During the study period, more adult individuals were counted than sub-adults and young ones. The age ratio of young to all other individuals was 1.00:4.45 and young to mature or adult aged ratio was 1.00:2.43 during both wet and dry seasons (Table 4). One Way ANOVA test indicated that there was no significant difference between wet and dry seasons $(\mathrm{F}=0.072, \mathrm{df}=1, \mathrm{p}=0.795)$. Here also, the ratio of young to an adult female was 1.00:1.40 and 1.00:1.36 during dry and wet seasons, respectively.

Table 4. Proportions of different age and sex categories of the Colobus guereza gallarum recorded during the dry and wet seasons.

\begin{tabular}{|c|c|c|c|c|c|c|c|c|}
\hline \multirow{3}{*}{$\begin{array}{l}\text { Season } \\
\text { Season }\end{array}$} & \multicolumn{5}{|c|}{ Sex and Age categories } & \multicolumn{3}{|l|}{ Ratio } \\
\hline & \multicolumn{2}{|c|}{ Sex } & \multicolumn{3}{|l|}{ Age } & \multirow{2}{*}{$\begin{array}{l}\text { Sex } \\
\text { M:F }\end{array}$} & \multicolumn{2}{|l|}{ Age } \\
\hline & $\mathbf{A M}$ & $\mathbf{A F}$ & SAM & SAF & $\mathbf{Y}$ & & Yg: Others & Yg: Ad \\
\hline Dry & 23 & 28 & 21 & 21 & 20 & $1.00: 1.11$ & $1.00: 4.65$ & $1.00: 2.55$ \\
\hline Wet & 21 & 30 & 21 & 22 & 22 & $1.00: 1.24$ & $1.00: 4.27$ & $1.00: 2.32$ \\
\hline Total & 44 & 58 & 42 & 43 & 42 & $1.00: 1.17$ & $1.00: 4.45$ & $1.00: 2.43$ \\
\hline
\end{tabular}

$(\mathrm{AM}=$ Adult male, $\mathrm{AF}=$ Adult female, $\mathrm{SAM}=$ Sub-adult male, $\mathrm{SAF}=$ Sub-adult female, $\mathrm{Y}=$ Young $)$ 
Community perception and Threats to Colobus guereza gallarum

The perception of communities towards the species indicated as the majority of respondents have a positive outlook towards the species. Of the total 341 respondents, $308(90.32 \%)$ of respondents agreed to the importance of conservation for C. g. gallarum. However, 33 (9.68\%) of respondents disagreed with threats caused by humans on the species as well as habitat alteration of the species. The result also revealed the less damage caused by the species towards human's property (Table 5).

Table 5. Views of the local community on Colobus guereza gallarum.

\begin{tabular}{|c|c|c|c|c|c|}
\hline \multirow{3}{*}{ No } & \multirow{3}{*}{ Statement } & \multicolumn{4}{|c|}{ Response in percent } \\
\hline & & \multicolumn{2}{|l|}{ Yes } & \multicolumn{2}{|l|}{ No } \\
\hline & & $\mathbf{N}$ & $\%$ & $\mathbf{N}$ & $\%$ \\
\hline 1 & Do you know Colobus guereza gallarum? & 310 & 90.91 & 31 & 9.09 \\
\hline 2 & Do you have positive perception towards the species? & 308 & 90.32 & 33 & 9.68 \\
\hline 3 & Do you think conservation of the species is important? & 337 & 98.83 & 4 & 1.17 \\
\hline 4 & Is the population trend of Colobus guereza increasing? & 298 & 87.39 & 43 & 12.61 \\
\hline 5 & Do humans influence the existence of Colobus guereza in the park? & 93 & 27.27 & 248 & 72.73 \\
\hline 7 & Is there an alteration in the habitat nature of Colobus guereza in the area? & 107 & 31.38 & 234 & 68.62 \\
\hline
\end{tabular}

Table 6 showed the local community were also had six major perceptions why they have a positive attitude. Of these, tourism value $(44.57 \%)$, cultural values $(28.74 \%)$ and ecological values $(16.42 \%)$ of Colobus guereza gallarum were the first three main reasons (perceptions) of positive attitudes of the community.

Table 6. Positive perception of local community towards Colobus guereza gallarum.

\begin{tabular}{llll}
\hline No. & Statement & Number of records & Percent \\
\hline 1 & It is a natural gift & 10 & 2.93 \\
2 & Doesn't cause damage to humans & 14 & 4.11 \\
\hline
\end{tabular}

\begin{tabular}{llll}
\hline No. & Statement & Number of records & Percent \\
\hline 3 & Ecological values & 56 & 16.42 \\
4 & Tourism value & 152 & 44.57 \\
5 & Aesthetic value & 11 & 3.23 \\
6 & Cultural values & 98 & 28.74 \\
\hline
\end{tabular}

According to direct field observation of the habitat of the animal, there were recorded six major anthropogenic threats of Colobus guereza gallarum (Table 7). Of these threats, livestock resource competition $(33.33 \%)$ was the first threat followed by farming (17.86\%) and logging of trees (15.48\%).

Table 7. Threats to Colobus guereza gallarum.

\begin{tabular}{llll}
\hline No. & Type of threats & Encounter rate \\
\hline 1 & Logging & 13 & Percent \\
2 & Settlement & 8 & 15.48 \\
3 & Farming & 9.52 & 15 \\
4 & Livestock presence & 28 & 17.86 \\
5 & Direct human disturbance through behave setting, fence making and pollution & 11 & 9 \\
6 & Fuel wood collection & 83.33 & 13.10 \\
Total & & 10.71 \\
\hline
\end{tabular}

\section{Discussion}

Guerezas are tied to habitats that have trees and are present in forests. They are found in highland or mountain forests $[18,19]$. The present study also agreed to this habitat association and distribution. This preference is likely attributable to high species diversity of food trees in some secondary growth forests and may also be explainable in terms of milder chemical defenses in secondary growth species [19]. Moreover, the present study revealed that $C . g$. gallarum were seen in habitats characterized by forests composed of tall trees.

The result of the present study revealed that the populations of Colobus guereza gallarum structured with 44 are adult males, 58 adult females, 42 sub-adult males, $43 \%$ sub-adult females and the remaining 42 were young individuals. According to [20], the usual composition of guereza groups includes one adult male, several adult females, and immature individuals. Also in this subspecies of the present study, females were predominant than males and young in the populations of Gureza both in dry and wet periods, which might indicate that the population has a potential to increase in number. Possible reasons for unequal postnatal sex ratio may be due to the increased mortality of males because they were more exposed to predation than females as they are less vigilant during feeding. The solitary nature of males forming small groups enhances the vulnerability of males towards predation. The explanation for male mortality is also that bachelor males are distributed often in less favorable habitats as the central core area is inhabited by territorial adult males [18].

However, the ratio of young to other individuals (1.00: 4.65 ) in the present study may show a declining trend of the animal. The possible reasons might be a higher percentage of young mortality or predation because they are unable to 
escape from predators at this stage, the presence of small breeding females and the young have a tendency to be kept hidden under bushes or other shaded areas and they could have been underestimated during the survey.

Habitat loss is the primary threat facing species worldwide [21]. This loss of habitats is a result of habitat destruction mainly influenced by human activities and other inevitable factors. Likewise, the major threats of Colobus guereza gallarum observed during the study period included intensive livestock grazing, intensification of farming activities, logging, and other direct human disturbances. Fuel wood collection, overgrazing, and deforestation are the main threats to biological resources in Bale Mountains National Park [22]. Human disturbance of tropical forest is not only leading to habitat destruction but also to massive habitat fragmentation [23]. The current threats of Colobus guereza are primarily driven by deforestation, fuel wood collection, timber, and charcoal production $[24,26]$. This has led to widespread forest fragmentation. Colobus monkeys being highly arboreal are especially vulnerable to these threats, as they require leaves, fruits and seeds for survival [24, 25].

\section{Conclusion}

C. g. gallarum is one of the known groups of monkeys that have a great potential for tourism activities in the study area. The conflict reported in the area is insignificant. Logging, farmland expansion and settlement were the main observed threats to species in the area. The study also indicated that communities have positive perception towards the species. Despite its great importance for communities through tourism, cultural benefits, and ecological role, it is facing anthropogenic threats that can affect its future existence. Hence, the following points are suggested as recommendations for appropriate management of $C . g$. gallarum in Bale Mountains National Park.

Continuous follow up on the number of $C$. g. gallarum is essential for proper management and sustainable protection. The protection of C. g. gallarum habitat quality is crucial to keep the animal in their good natural condition. The human destruction of tree species which are most preferred by $C$. $g$. gallarum should have more protection because habitat loss will affect the sustainable existence of the species. Ecotourism activities should be promoted as they are main ways by which communities obtain benefits through conservation of species. Conservation program for endemic C. g. gallarum in the BMNP should be established. Further study should be promoted to know more about the population dynamics, reproduction and other ecological and behavioral aspect of C. g. gallarum in Bale Mountains National Park.

\section{References}

[1] Yalden, D. W. (1983). The extent of high ground in Ethiopia compared to the rest of Africa. SINET 6: 35- 40.

[2] Fishpool, J. and Evans, M. I. (2001). Important Bird Areas in
Africa and Associated Islands; Priority Sites for Conservation. Piscus Publishers, Cambridge.

[3] IBC (2007). Bale Mountain National Park Management Plan (2007- 2017). Institute of Biodiversity Conservation, Addis Ababa.

[4] Jensz, K. and Finley, L. (2011). Species profile for Colobusguereza. Latitude Environmental Consultants Pty Ltd. Hobart, Tasmania.

[5] Kingdon, J., Struhsaker, T., Oates, J. F., Hart, J. \& Groves, C. P. (2008). Colobus guereza. In: IUCN 2011. IUCN Red List of Threatened Species. Version 2011.1. <www.iucnredlist.org>. Downloaded on 10 October 2017.

[6] Nkurunungi, J., and Stanford, C. (2003). Behavioral Ecology of Sympatric Chimpanzees and Gorillas in Bwindi Impenetrable National Park, Uganda: Diet. International Journal of Primatology. 24 (4): 902-918.

[7] Aramde Fetene, Girma Mengesha and TsegayeBekele (2011). Spatial distribution and habitat preferences of selected large mammalian species in the NechSar NationalPark (NSNP), Ethiopia. Nature and Science. 9 (3): 80-90.

[8] Alers M, Bovarnick A, Boyle T, Mackinnon K, Sobrevila C, (2007). Reducing threats to protected areas: Lessons from the field. A Joint UNDP and World Bank GEF Lessons Learned study. p. 84.

[9] Gashaw, T. (2015). Threats of Bale Mountains National Park and solutions, Ethiopia. Journal of Physical Science and Environmental Studies, 1 (2): 10-16.

[10] Norman Myers, Russell A. Mittermeier, Cristina G. Mittermeier, Gustavo A. B. da Fonseca and Jennifer Kent (2000). Biodiversity hotspots for conservation priorities. Nature 403: 853-858.

[11] Bird Life International (2001). Important Bird Areas of Africa and Associated Islands, Priority Areas for Conservation. Pisces Publishers, Cambridge.

[12] Fashing, P. J and Cords, M. (2000). Diurnal Primate Densities and Biomass in the Kakamega Forest: An Evaluation of Census Methods and a Comparison with Other Forests. American Journal of Primatology 50:139-152.

[13] Leca, Jean-Baptiste, Gunst, N., Rompis, A., Soma, G. Arta Putra, I. G. A. and Wandia, I. N. (2013). Population Density and Abundance of Ebony Leaf Monkeys (Trachypithecusauratus) in West Bali National Park, Indonesia. Primate Conservation 2013 (26): 133-144.

[14] Addisu Mekonnen, Afwork Bekele, Hemson, G., Eyob Teshome and Anagaw Atickem (2010). Population size, and habitat preference of the Vulnerable Bale monkey (Cholorocebus djamdjaminesis) in Odobullo forest and its distribution across the Bale Mountains, Ethiopia. Oryx 44: 558-563.

[15] Wallace, B. R., Painter, R. L. E. and Taber, A. B. (1998). Primate diversity, habitat preference and population density in Noel Kempff Mercado National Park. Samba Cruz Department, Bolivia. Am. J. Primatol. 46:197-211.

[16] Peres, C. A. (1999). General guidelines for standardizing line transect surveys of tropical forest primates. Neotrop. Primatol. 7:11-16. 
[17] Israel, G. D. (1992) Determining Sample Size. University of Florida Cooperative Extension Service, Institute of Food and Agriculture Sciences, EDIS, Florida.

[18] Oates J. F., Davies A. G. (1994). What are the colobines? In: Oates JF, Davies AG (eds). Colobine Monkeys: their ecology, behaviour and evolution. 1-9. Cambridge University Press, UK.

[19] Jeremiah S. Lwanga 2006 The influence of forest variation and possible effects of poaching on duiker abundance at Ngogo, Kibale National Park, Uganda. African journal of Ecology. 44 (2). 209-218.

[20] Fashing, P. J. (2001a). Activity and ranging patterns of guerezas in the Kakamega forest: Intergroupvariation and implications for intragroup feeding competition. Int. $J$. Primatol. 22:549-577.

[21] Eustace, A., Kisingo, A. W., Kahana, L. W., and Lyimo, E. H. (2015). Activity Patterns of Black and White Colobus Monkey (Colobusguerezacaudatus) in Rau Forest Reserve, Tanzania. Research and Reviews: Journal of Ecology and Environmental Sciences. 3 (4):17-24.
[22] Israel Petros, Kassahun Abie and Berhanu Esubalew (2016). Threats, Opportunities and Community perception of Biological resource conservation in Bale mountains national park case of Dinsho districs, Ethiopia. Int. Res. J. Biological Sci. 5 (4): 6-13.

[23] DeGama-Blanchet, H. N and Fedigan, L. M. (2005). The Effects of Forest Fragment Age, Isolation, Size, Habitat Type, and Water Availability on Monkey Density in a Tropical Dry Forest. Springer.

[24] Anderson J., Cowlishaw, Rowcliffe J. M.. (2007). Effects of forest fragmentation on the abundance of Colobusangolensispalliatusin Kenya's coastal forests. International Journal of Primatology 28: 637-655.

[25] Gómez-Posada, C., Martínez, J., Giraldo, P. And Kattan, G. H. (2007). Density, habitat use, and ranging patterns of red howler monkeys in a colombian andean forest. Neotropical Primates 14: 2-10.

[26] Harris, T. R. (2006). Between-group contest competition for food in a highly folivorous population of black and white colobus monkeys (Colobusguereza). Behavioral Ecologyand Sociobiology 61: 317-329. 